\title{
Moxidectin inhibits glioma cell viability by inducing G0/G1 cell cycle arrest and apoptosis
}

\author{
DANDAN SONG ${ }^{1 *}$, HONGSHENG LIANG ${ }^{2 *}$, BO QU ${ }^{1}$, YIJING LI $^{3}$, JINGJING LIU $^{1}$, \\ CHEN CHEN $^{1}$, DAMING ZHANG ${ }^{2}$, XIANGTONG ZHANG ${ }^{2}$ and AILI GAO ${ }^{1}$

\begin{abstract}
${ }^{1}$ School of Life Science, Northeast Agricultural University, Harbin, Heilongjiang $150030 ;{ }^{2}$ Key Laboratory of Neurosurgery, College of Heilongjiang Province; The First Affiliated Hospital of Harbin Medical University, Harbin, Heilongjiang 150001; ${ }^{3}$ College of Veterinary Medicine, Northeast Agricultural University, Harbin, Heilongjiang 150030, P.R. China
\end{abstract}

Received February 19, 2018; Accepted June 26, 2018

DOI: $10.3892 /$ or.2018.6561

\begin{abstract}
Moxidectin (MOX), a broad-spectrum antiparasitic agent, belongs to the milbemycin family and is similar to avermectins in terms of its chemical structure. Previous research has revealed that milbemycins, including MOX, may potentially function as effective multidrug resistance agents. In the present study, the impact of MOX on the viability of glioma cells was examined by MTT and colony formation assay, and the molecular mechanisms underlying MOX-mediated glioma cell apoptosis were explored by using flow cytometry and apoptosis rates. The results demonstrated that MOX exerts an inhibitory effect on glioma cell viability and colony formations in vitro and xenograft growth in vivo and is not active against normal cells. Additionally, as shown by western blot assay, it was demonstrated that MOX arrests the cell cycle at the G0/G1 phase by downregulating the expression levels of cyclin-dependent kinase (CDK)2, CDK4, CDK6, cyclin D1 and cyclin E. Furthermore, it was revealed that MOX is able to induce cell apoptosis by increasing the Bcl-2-associated $\mathrm{X}$ protein/B-cell lymphoma 2 ratio and activating the caspase-3/-9 cascade. In conclusion, these results suggest that MOX may inhibit the viability of glioma cells by inducing cell apoptosis and cell cycle arrest, and may be able to function as a potent and promising agent in the treatment of glioma.
\end{abstract}

\section{Introduction}

Glioma is characterized by extremely aggressive invasive and potent malignant abilities with a high proliferation rate (1). At present, comprehensive treatment types (typically including surgical resection, radiotherapy and auxiliary-assisted

Correspondence to: Professor Aili Gao, School of Life Science, Northeast Agricultural University, 600 Changjiang Road, Xiangfang, Harbin, Heilongjiang 150030, P.R. China

E-mail: gaoaili2004@163.com

${ }^{*}$ Contributed equally

Key words: moxidectin, glioma, viability, apoptosis, cell cycle arrest chemotherapy) are widely used clinically; however, the average survival time remains only $\sim 1$ year (2). Additionally, the majority of chemosensitizers demonstrate negative side-effects and/or little efficacy against glioma $(3,4)$. Therefore, the development of novel, more potent chemotherapy agents with fewer side-effects and higher efficacy is a priority in glioma treatment research.

Moxidectin (MOX), derived from the actinomycete Streptomyces cyanogriseus subsp. Noncyanogenus $(5,6)$, is a third generation macrocyclic lactone with potent insecticide activity, belonging to the milbemycin family $(7,8)$. Previous research has revealed that certain macrocyclic lactones, including MOX, with lower toxicity are used widely for the treatment of internal and external parasites in cattle, sheep, deer and horses (6,9-12). MOX is currently being used in phase III clinical trials in the treatment of filarial Onchocerca volvulus infection in humans, which indicates that MOX is safe and well tolerated in humans at doses between 3 and $36 \mathrm{mg}(6,13)$.

In one previous study, some compounds that belong to the milbemycin family including MOX were found to reverse the multidrug resistance (MDR) of MCF-7/adr cells. Study of the mechanisms underlying the effects of milbemycins on p-glycoprotein (P-gp)-mediated MDR demonstrated that the milbemycins significantly increased the intracellular accumulations of adriamycin and Rh123 via inhibiting P-gp transport function, which revealed that MOX may function as an effective multidrug resistance agent. Additionally, it was demonstrated that MOX was partially effective in killing non-drug-resistant tumor cells (14). Previously, macrocyclic lactones including avermectins (ivermectin) have been revealed to be effective in inhibiting the proliferation of tumor cells (Hep-2 and P388 cells) $(15,16)$. Furthermore, ivermectin suppressed breast cancer cell growth and induced glioblastoma cell death in vitro and in vivo $(17,18)$. MOX and ivermectin, which are similar in chemical structure, partially share certain physicochemical and pharmacological properties. They also have broad-spectrum activity against nematodes and arthropods (19). MOX differs from ivermectin primarily by the lack of a sugar moiety attached to the $\mathrm{C} 13$ of the macrocyclic ring (20). Previous publications have demonstrated that both compounds have a number of similar mechanisms of action and are part of the antiparasitic spectrum (21-23). 
To the best of our knowledge, there have been no previous reports on the use of MOX in cancer treatment. The present study was carried out to investigate the ability of MOX to treat glioma, and to explore its potential molecular mechanisms in vitro and in vivo.

\section{Materials and methods}

Reagents and antibodies. MOX was purchased from Sigma-Aldrich/Merck KGaA (Darmstadt, Germany; European Pharmacopoeia Reference Standard), and a purity of $>95 \%$. MOX was dissolved in dimethyl sulfoxide (DMSO) prior to use. Cells were treated with MOX premixed cell culture Dulbecco's modified Eagle's medium (DMEM) containing $10 \%$ fetal bovine serum (FBS). The DMSO concentration did not exceed $0.1 \%$ of the total volume. MTT, diaminobenzidine (DAB), polyvinylidene fluoride (PVDF) membranes, hematoxylin and eosin (H\&E) were purchased from Sigma-Aldrich; Merck KGaA. Propidium iodide (PI)/Annexin V fluorescein isothiocyanate (FITC) were purchased from Beyotime Institute of Biotechnology (Haimen, China). Antibodies used in the present study were against $\mathrm{Bcl}-2$-associated $\mathrm{X}$ protein (Bax; cat. no. 2774; Cell Signaling Technology, Inc., Danvers, MA, USA), B-cell lymphoma 2 (Bcl-2; cat. no. 3498; Cell Signaling Technology, Inc.), cyclin-dependent kinase (CDK)2 (cat. no. 2546; Cell Signaling Technology, Inc.), CDK4 (cat no. 12790; Cell Signaling Technology, Inc.), CDK6 (cat. no. 13331; Cell Signaling Technology, Inc.), cleaved caspase-3 (cat. no. bs-0081R; Bioss, Inc., Beijing, China), cleaved caspase-9 (cat. no. bs-0049R; Bioss, Inc.), cyclin D1 (cat. no. 2922; Cell Signaling Technology, Inc.), cyclin E (cat. no. SRP5345; Sigma-Aldrich; Merck KGaA), Ki-67 (cat no. 9129; Cell Signaling Technology, Inc.), $\beta$-actin (cat. no. A1978; Sigma-Aldrich; Merck KGaA), goat anti-rabbit immunoglobulin G (IgG) (H+L)-horseradish peroxidase (HRP; cat. no. LK2001; SunGene GmbH, Gatersleben, Germany) and goat anti-mouse IgG (H+L)-HRP (cat. no. ZB-2305; OriGene Technologies, Inc., Rockville, MD, USA).

Cell culture. Rat C6 glioma cells and human U251 glioma cells were obtained from The First Affiliated Hospital of Harbin Medical University (Harbin, China). SVG p12 was purchased from Wuhan YiPu Biotech Co., Ltd. (Wuhan, China). Cells were cultured in DMEM supplemented with 10\% FBS and 1\% penicillin and streptomycin at $37^{\circ} \mathrm{C}$ in a humidified incubator with $5 \% \mathrm{CO}_{2}$.

Cell viability assay. Cell viability and cell number were determined using an MTT (purity >95\%) assay. C6 $\left(2.0 \times 10^{3}\right.$ cells/well $), \mathrm{U} 251\left(1.0 \times 10^{4}\right.$ cells/well $)$ and normal human astrocyte cells (SVG p12, 7.0 $10^{3}$ cells/well) were respectively seeded into 96 -well plates with $100 \mu \mathrm{l}$ culture medium and treated with the indicated concentrations $(0,10$, $20,30,40$ and $50 \mu \mathrm{mol} / \mathrm{l})$ of $\mathrm{MOX}$ for $48 \mathrm{~h}$ at $37^{\circ} \mathrm{C}$. Next, $20 \mu 1 \mathrm{MTT}(5 \mathrm{mg} / \mathrm{ml})$ solution was added to each well, and the cells were incubated for $4 \mathrm{~h}$ at $37^{\circ} \mathrm{C}$. Once the medium was carefully removed, $150 \mu \mathrm{l}$ of DMSO was added and agitated to dissolve the formazan crystals. The absorbance at $490 \mathrm{~nm}$ was measured using an enzyme-linked immunosorbent assay reader (Nanjing Huadong Electronics Group Co., Ltd., Nanjing,
China). For relative quantification, the value of absorbance in each group was normalized to that of the control group.

Colony formation assay. To analyze the sensitivity of the cells to MOX, an in vitro colony formation assay was performed.

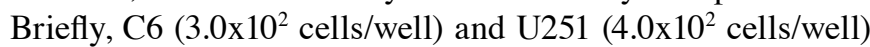
cells were seeded in 6 -well plates for $24 \mathrm{~h}$ then treated with various concentrations of $\operatorname{MOX}(0,10,15$ and $20 \mu \mathrm{mol} / \mathrm{l})$ at $37^{\circ} \mathrm{C}$. The cultures were maintained at $37^{\circ} \mathrm{C}$ in a $5 \% \mathrm{CO}_{2}$ incubator for 10 days, which allowed the viable cells to grow into macroscopic colonies. Then, the medium was removed, and the colonies were counted subsequent to being stained with $0.1 \%$ crystal violet (Sigma-Aldrich; Merck KGaA) at room temperature for $20 \mathrm{~min}$. Quantification of colony formation was also performed using ImageJ software (V 2.0; National Institutes of Health, Bethesda, MD, USA).

Flow cytometry. C6 $\left(2.5 \times 10^{5}\right.$ cells/well $)$ and U251 $\left(2.8 \times 10^{5}\right.$ cells/well) cells were seeded into 6-well plates and treated with various concentrations of $\operatorname{MOX}(0,10,15$ and $20 \mu \mathrm{mol} / \mathrm{l})$. For cell cycle analysis, the cells were treated at $37^{\circ} \mathrm{C}$ for 24 and $48 \mathrm{~h}$, washed with ice-cold phosphate-buffered saline (PBS; Biotopped, Beijing, China), and collected cell suspensions were fixed in $70 \%$ ice-cold ethanol at $4^{\circ} \mathrm{C}$ for $24 \mathrm{~h}$. Then, the fixed cells were washed twice with PBS and stained with PI for $20 \mathrm{~min}$ at room temperature away from light. For apoptosis analysis, cells were treated $\mathrm{MOX}$ at $37^{\circ} \mathrm{C}$ for $48 \mathrm{~h}$, washed twice with ice-cold PBS, and then cell suspensions were collected, suspended with Annexin V binding buffer and Annexin V-FITC/PI, and the mixture was incubated for $20 \mathrm{~min}$ at room temperature in the dark. The cell cycle distribution and apoptosis ratio were measured using a BD Biosciences FACSCalibur flow cytometer (BD Biosciences, Franklin Lakes, NJ, USA). The DNA content of the cell cycle was analyzed using ModFit LT v3.3 application software (Verity Software House Inc., Topsham, ME, USA).

Transmission electron microscopy (TEM). C6 and U251 cells were treated with $\mathrm{MOX}(20 \mu \mathrm{mol} / \mathrm{l})$ at $37^{\circ} \mathrm{C}$ for $48 \mathrm{~h}$, and untreated cells served as the control group. Then, the cells were harvested, washed twice with PBS and fixed with a solution of $2.5 \%$ glutaraldehyde in PBS at $4^{\circ} \mathrm{C}$ for $2 \mathrm{~h}$, and post fixed with $1 \%$ phosphate-buffered osmium tetroxide at $4^{\circ} \mathrm{C}$ for $1 \mathrm{~h}$. Next, the cell were dehydrated using a graded series of ethanol solutions $(30,50,70,90$ and $100 \%), 8$ or $10 \mathrm{~min}$ at a time, transferred to propylene oxide and embedded in epon araldite (Polybed 812; Polysciences, Inc., Warrington, PA, USA). The ultrathin sections were observed using a JEM-100CX transmission electron microscope (H-7650; Shanghai Yongming Automatic Equipments Co., Ltd., Shanghai, China) and representative images were photographed and analyzed.

Western blotting. C6 and U251 cells were treated with various concentrations of $\operatorname{MOX}(0,10,15$ and $20 \mu \mathrm{mol} / \mathrm{l})$ for $48 \mathrm{~h}$, and then total protein from the cells was extracted using radio immunoprecipitation assay buffer, which was subjected to sodium dodecyl sulfate-polyacrylamide gel (12\%) electrophoresis and then transferred to PVDF membranes. Following blocking with $5 \%$ skim milk for $1 \mathrm{~h}$, the membranes were incubated at $4^{\circ} \mathrm{C}$ overnight with the following antibodies: 
anti-CDK2 (1:1,000), anti-CDK4 (1:1,000), anti-CDK6 $(1: 1,000)$, anti-cyclin D1 $(1: 1,000)$, anti-cyclin E $(1: 1,000)$, anti-Bax (1:1,000), anti-Bcl-2 (1:1,000), anti-cleaved caspase-3 (1:800), anti-cleaved caspase-9 (1:800) and anti- $\beta$-actin $(1: 1,000)$. Subsequent to washing three times with Tris-buffered saline Tween (TBST; Solarbio, Beijing, China), HRP-conjugated secondary antibodies $(1: 5,000)$ were used in conjunction with MiniChemi-Imager (Beijing Sage Creation Co., Ltd., Beijing, China) for visualization. The intensity of the western blotting bands was measured using ImageJ software (version 2.0; National Institutes of Health).

Animal models. All studies were performed in accordance with the ethical standards of the institutional and/or national research committee (Harbin Vic Biological Technology Development Co., Ltd., Harbin, China) and with the 1964 Helsinki declaration and its later amendments or comparable ethical standards. Ethical approval was obtained for the animal experiments. Female BALB/c mice (Beijing HFK Bioscience Co., Ltd, Beijing, China) at 5 weeks of age and an average weight of 19-23 $\mathrm{g}$ were used. They were housed in plastic cages under standard conditions and had access to rodent chow and water ad libitum. For the glioma cancer model, U251 cells $\left(2.0 \times 10^{6}\right)$ were suspended in PBS and engrafted in the dorsal of nude mice. When the tumor volumes reached $70 \mathrm{~mm}^{3}$, mice were assigned randomly into two groups receiving $0.1 \mathrm{ml}$ saline or $20 \mathrm{mg} / \mathrm{kg}$ MOX/mouse/day by peritoneal injection for 3 weeks. Saline or MOX were injected intraperitoneally into mice daily. The volume of tumors were measured every four days by using a vernier caliper and calculated as length $(\mathrm{mm}) \mathrm{x}$ width ${ }^{2}\left(\mathrm{~mm}^{2}\right) \times 1 / 2$. The mice were euthanized using $\mathrm{CO}_{2}$ for analysis following four weeks and the maximum allowable tumor volume was no $>800 \mathrm{~mm}^{3}$. The mice were sacrificed subsequent to being anesthetized using barbiturates and tumor tissues were isolated and frozen in liquid nitrogen or fixed in $10 \%$ formalin immediately.

Immunohistochemistry. Immunohistochemicaly staining was performed on paraffin-embedded tissues from the harvested tumors. Sections (5 $\mu \mathrm{m}$-thickness) were oven dried at $60^{\circ} \mathrm{C}$ for $1 \mathrm{~h}$. Tissue sections were then deparaffinized with xylene (absolute) and hydrated with ethyl alcohol (100, 90, 75, 50 and $30 \%$ ). The sections were labeled with antibodies for Ki-67 (1:400), cleaved caspase-3 (1:300) and cleaved caspase-9 $(1: 300)$ followed by HRP-conjugated secondary antibodies $(1: 3,000)$ using DAB reagents as a substrate, and then counterstained with hematoxylin at room temperature for $1 \mathrm{~min}$. The negative control consisted of omitting the primary antibodies. The images were captured with digital microscope camera (E100) and analyzed with ImageJ software (version 2.0; National Institutes of Health).

$H \& E$ staining and terminal deoxynucleotidyl transferase-mediated dUTP nick end labeling (TUNEL) assay. The tumors from each mouse were immediately fixed in formaldehyde (10\%) for $24 \mathrm{~h}$ at $4^{\circ} \mathrm{C}$ and embedded in paraffin at $60^{\circ} \mathrm{C}$ for $1 \mathrm{~h}$. Then, the tissues were sectioned at $5 \mu \mathrm{m}$ thickness, and stained with H\&E at room temperature for 1 min to assess the cytopathological features.
A TUNEL assay, which detects fragmented DNA, was performed using an In Situ Cell Death Detection kit to evaluate the apoptotic response of tumor tissues. Briefly, subsequent to being deparaffinized (xylene, absolute) and hydrated $(95,90,80,70$ and 50\%), slides were washed with PBS twice and incubated with proteinase $\mathrm{K}(20 \mu \mathrm{g} / \mathrm{ml})$ for $20 \mathrm{~min}$ at $37^{\circ} \mathrm{C}$. Following a second round of washes using PBS, slides were incubated with a TUNEL reaction mixture prepared freshly for $1 \mathrm{~h}$ at $37^{\circ} \mathrm{C}$ in a moist chamber. Subsequent to being washed twice with PBS, the slides were observed under $\mathrm{x} 40$ fluorescence microscopy.

Quantitative and statistical analysis. For quantification, Ki-67, cleaved caspase-3 and caspase-9-staining intensity was measured from the number of positive cell nuclei in $25 \%$ fields using ImageJ software (version 2.0). All areas were chosen randomly from all sections. The intensity of bands in western blotting was also measured by ImageJ software. The values subsequent to normalizing to the loading control in the control groups were set as 1.0.

All experiments were performed at least three times. Data are presented as the mean \pm standard deviation (SD). One-factor analysis of variance (ANOVA) test was used to assess the differences among all the experiment and control groups. The Dunnett's test was employed for post-hoc comparison of the three experimental groups with the control group. GraphPad Prism Package (version 5.0; GraphPad Software, Inc., La Jolla, CA, USA) and SPSS version 20.0 statistical software (IBM Corp., Armonk, NY, USA) were used for statistical analysis. $\mathrm{P}<0.05$ was considered to be indicative of a statistically significant difference.

\section{Results}

MOX inhibits the viability of glioma cells in vitro. To examine the effect of MOX on glioma growth, an MTT assay was performed to measure the cell viability rates of C6, U251 and normal human astrocyte cells (SVG p12), respectively. As presented in Fig. 1A, treatment with MOX decreased the cell viability of glioma cells in a dose-dependent manner compared with the untreated glioma cells. Notably, MOX exerted a lesser effect on normal human astrocyte cells. The clonogenic capacity of C6 and U251 cells was examined, and it was revealed that MOX significantly inhibited colony formation and induced significant decreases in the colony formation ratio compared with the untreated cells (Fig. 1B and C). These results revealed that MOX inhibits glioma cell viability and has little effect on normal human astrocyte cells.

MOX induces apoptosis and the expression of apoptosis-associated proteins in glioma cells. To analyze the effect on the induction of apoptosis by MOX, the number of Annexin V-stained cells was determined using flow cytometry (Fig. 2A). As presented in Fig. 2B, C6 and U251 cells treated with MOX $(20 \mu \mathrm{mol} / \mathrm{l})$ had significantly induced apoptosis compared with the control groups, and the apoptotic rate of C6 and U251 cells was $19.10 \pm 3.59$ and $29.53 \pm 5.00 \%$, respectively. However, the apoptotic rate of the control cells (untreated C6 and U251 cells) was only $3.33 \pm 0.57$ and $2.93 \pm 0.34 \%$, respectively. Thus, MOX-induced apoptosis 
A

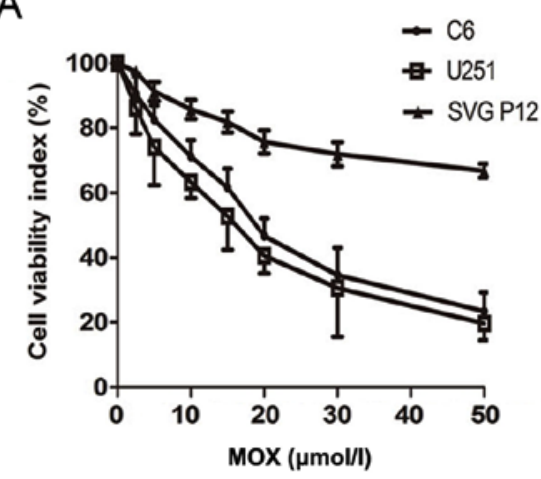

B

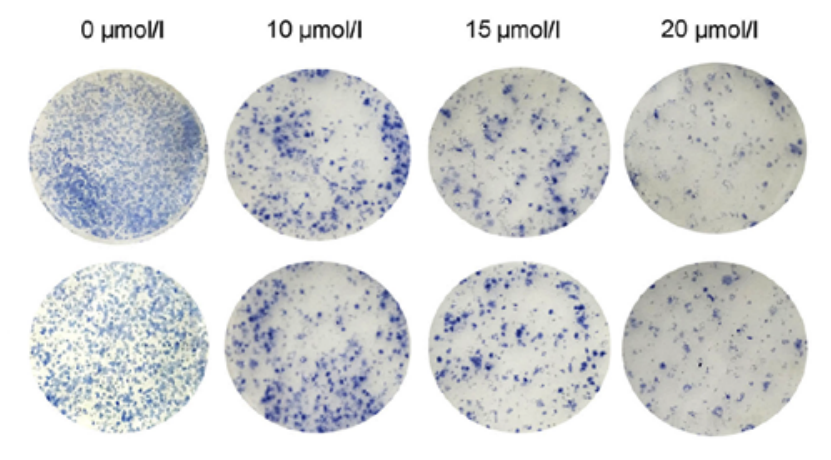

C
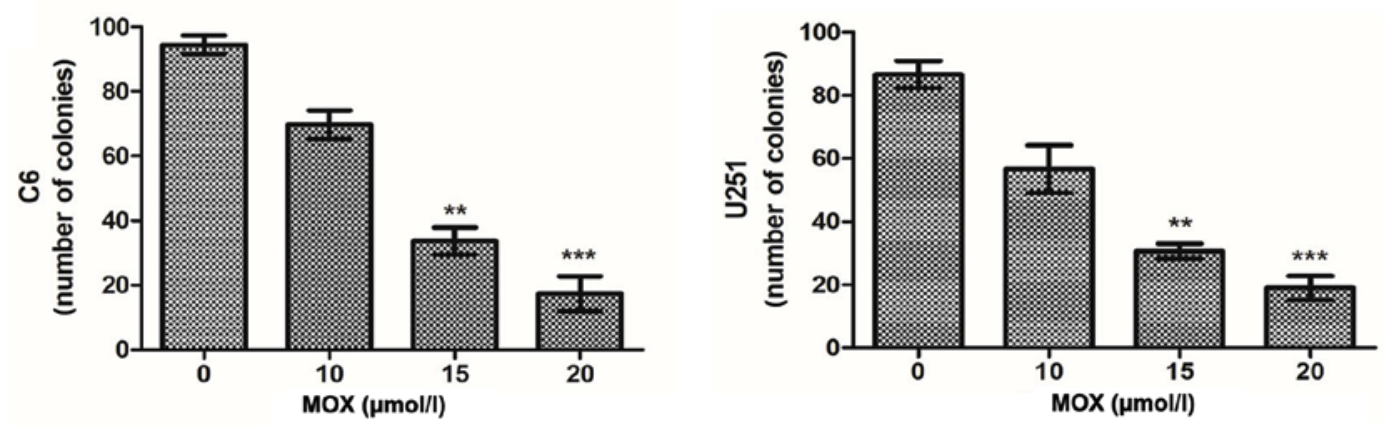

Figure 1. Inhibitory effect of MOX on C6, U251 and normal cells. (A) Cells were incubated in the absence or presence of MOX at various concentrations ( 0 , 10 , $20,30,40$ and $50 \mu \mathrm{mol} / \mathrm{l})$ for $48 \mathrm{~h}$, and cell viability was measured using an MTT assay. MOX inhibited the viability of C6 and U251 cells in a dose-dependent manner. MOX exhibited a lesser inhibitory effect on normal normal human astrocyte cells. (B) MOX suppressed colony formation in glioma cells. Cells were cultured in the indicated concentrations of MOX for 10 days. (C) Quantified graphs presenting the number of colonies. Data are presented as the mean \pm SD. ${ }^{* *} \mathrm{P}<0.01$ and ${ }^{* * *} \mathrm{P}<0.001$ vs. the control. MOX, moxidectin.

of C6 and U251 cells occurred in a dose-dependent manner compared with the control groups.

The mechanism of MOX-induced apoptosis was investigated by analyzing the expression levels of mitochondrial apoptosis proteins through western blotting. As presented in Fig. 2C, compared with the control group, C6 and U251 cells exposed to MOX demonstrated a dose-dependent reduction in the protein expression levels of the anti-apoptotic protein $\mathrm{Bcl}-2$, with a concomitant increase in the protein expression levels of the pro-apoptotic protein Bax. Additionally, the protein expression levels of cleaved caspase- 3 and cleaved caspase-9 were increased following treatment with MOX compared with control group.

MOX induces G0/G1 arrest by modulating cell cycleassociated proteins in glioma cells. To determine the effect of MOX on cell cycle arrest in C6 and U251 cells, the cell cycle distribution was investigated using flow cytometry (Figs. 3A and 4A). Interestingly, it was revealed that the accumulation of G0/G1 phase cells, a hallmark of apoptosis, was not notable until cells had been treated MOX for $48 \mathrm{~h}$ (Fig. 3B). As presented in Fig. 4B, the results revealed that MOX induced G0/G1 cell cycle arrest in C6 and U251 cells. The cell population at the G0/G1 phase gradually increased from $58.08 \pm 1.40$ to $78.03 \pm 1.66 \%$ for C6 cells, and from $50.58 \pm 1.50$ to $73.65 \pm 1.01 \%$ for $\mathrm{U} 251$ cells; and that of S phase decreased from $24.29 \pm 1.47$ to $14.65 \pm 1.04 \%$ for C6 cells, and from $29.44 \pm 1.57$ to $14.39 \pm 0.76 \%$ for $\mathrm{U} 251$ cells. These results revealed that MOX-induced G0/G1 cell cycle arrest of C6 and U251 cells was significantly higher compared with the untreated cells.

To investigate the underlying mechanism of the growth inhibitory effects of MOX, cell cycle regulators critical to the G0/G1 phase checkpoint were evaluated, including cyclin D1, cyclin E, CDK2, CDK4 and CDK6. The complex of cyclin D1 with CDK4 or CDK6 and the complex of cyclin E with CDK2 promote the transition of cells from the G0/G1 phase to the $\mathrm{S}$ phase $(24,25)$. Western blot analysis confirmed that MOX downregulated the protein expression levels of cyclin D1, cyclin E, CDK2, CDK4 and CDK6 compared with the control group (Fig. 4C).

MOX induces ultrastructural morphological changes in glioma cells. The morphological characteristics of apoptosis were analyzed using TEM. The results revealed that untreated cells presented no apoptotic characteristics with a complete cytoplasm and organelles (Fig. 5A and D). However, MOX-treated cells presented with typical apoptotic features: Including condensation and margination of nuclear chromatin, the formation of apoptotic bodies (Fig. 5B and E) and cytoplasmic hypervacuolization (Fig. 5C and F). These results suggested that MOX may promote apoptosis in glioma cells.

MOX suppresses U251 xenograft growth in vivo. Given the effect of MOX on glial cancer cell lines in vitro, an internal engraftment model was used to examine whether MOX 
A
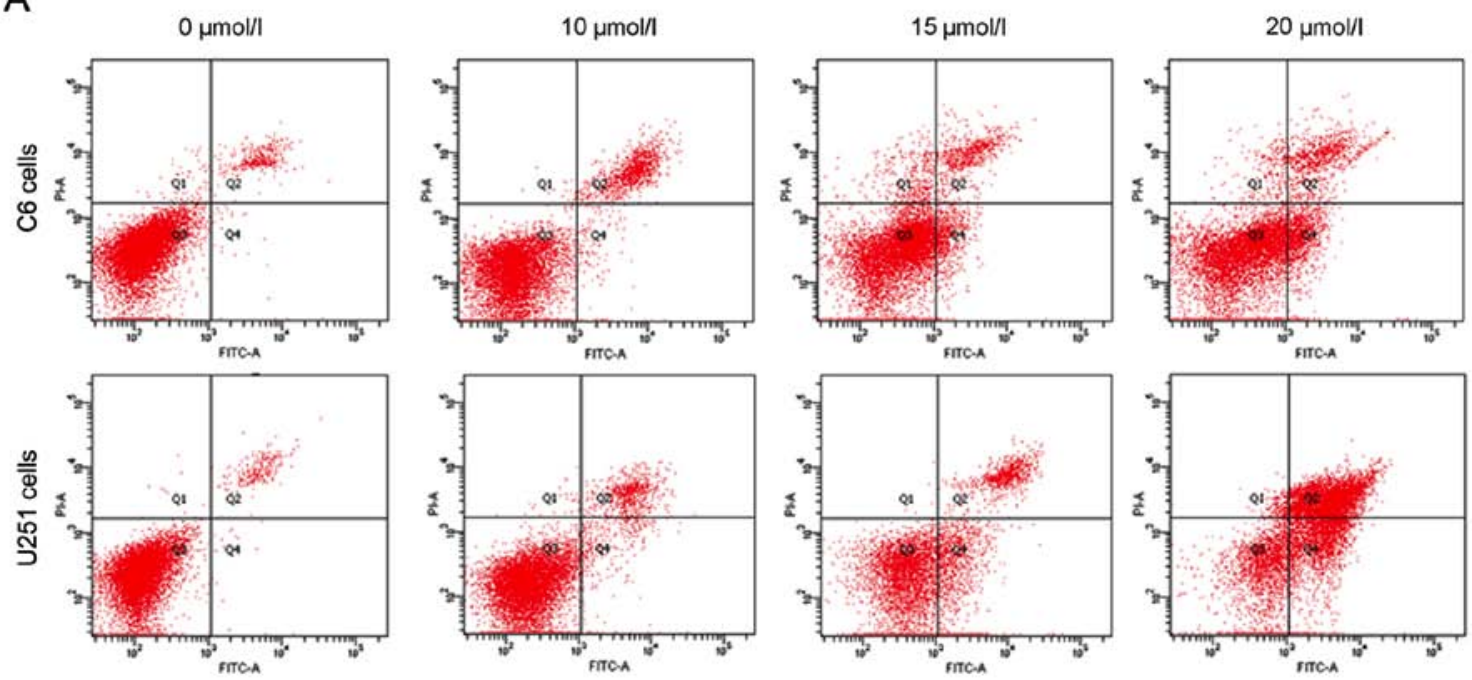

B

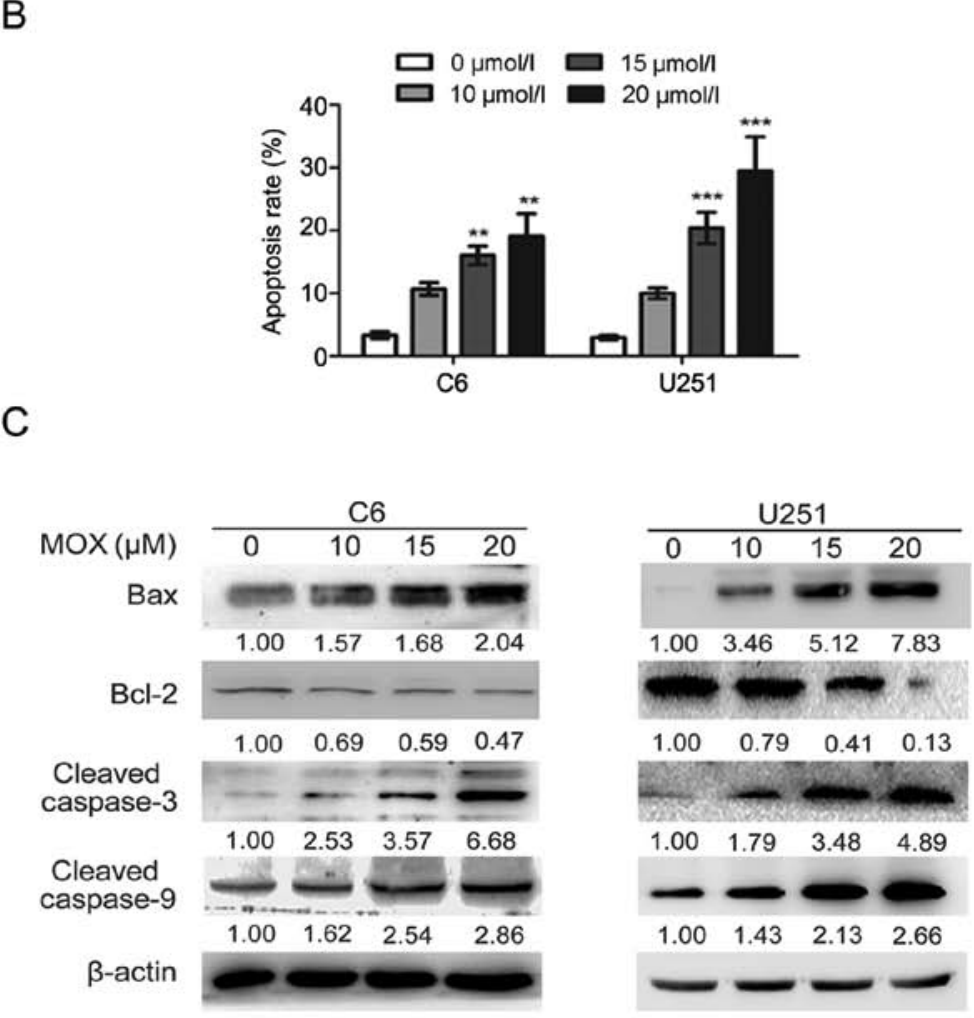

C

Figure 2. Apoptosis induction of MOX in C6 and U251 cells. Cells were treated with different concentrations of MOX $(0,10,15$ and $20 \mu$ mol/l) for $48 \mathrm{~h}$, stained with Annexin V-FITC/PI for 20 min at room temperature in the dark, and then analyzed using flow cytometry. Q2 plus Q4 areas were calculated as the apoptosis ratio. (A) Representative Annexin V-FITC/PI double staining flow plots for C6 and U251 cells. (B) The percentage of the apoptotic cell population. MOX induced apoptosis in C6 and U251 cells in a dose-dependent manner. (C) Effect of MOX on the protein expression levels of Bcl-2-assoxiated X protein, B-cell lymphoma 2, cleaved caspase-3 and caspase-9. C6 and U251 cells were treated with indicated MOX concentrations for $48 \mathrm{~h}$ and then subjected to western blotting analysis. Data are presented as the mean $\pm \mathrm{SD} .{ }^{* *} \mathrm{P}<0.01$ and ${ }^{* * * *} \mathrm{P}<0.001$ vs. the control. MOX, moxidectin; FITC, fluorescein isothiocyanate; PI, propidium iodide.

may induce similar effects in vivo. BALB/c nude mice were employed for the engraftment of human U251 cells. Macroscopically, xenografts treated with MOX grew at a slower rate compared with those treated with saline (Fig. 6A). Notably, tumor growth curves in mice treated with MOX had a relatively slow trend compared with the control group (Fig. 6B). No significant difference in the weights of the mice was observed between the test group and the control group on all measured days (Fig. 6C). H\&E staining and a TUNEL assay demonstrated a greater number of dead cells and an evident increase in the apoptotic proportion in MOX-treated tumor tissues compared with the saline treated tissues (Fig. 6D). To confirm the change in the proliferation status of the tumors, immunohistochemistry was performed to label Ki-67, cleaved caspase-3 and caspase-9, which are used clinically to assess the proliferative fraction in glioma cells. 
A
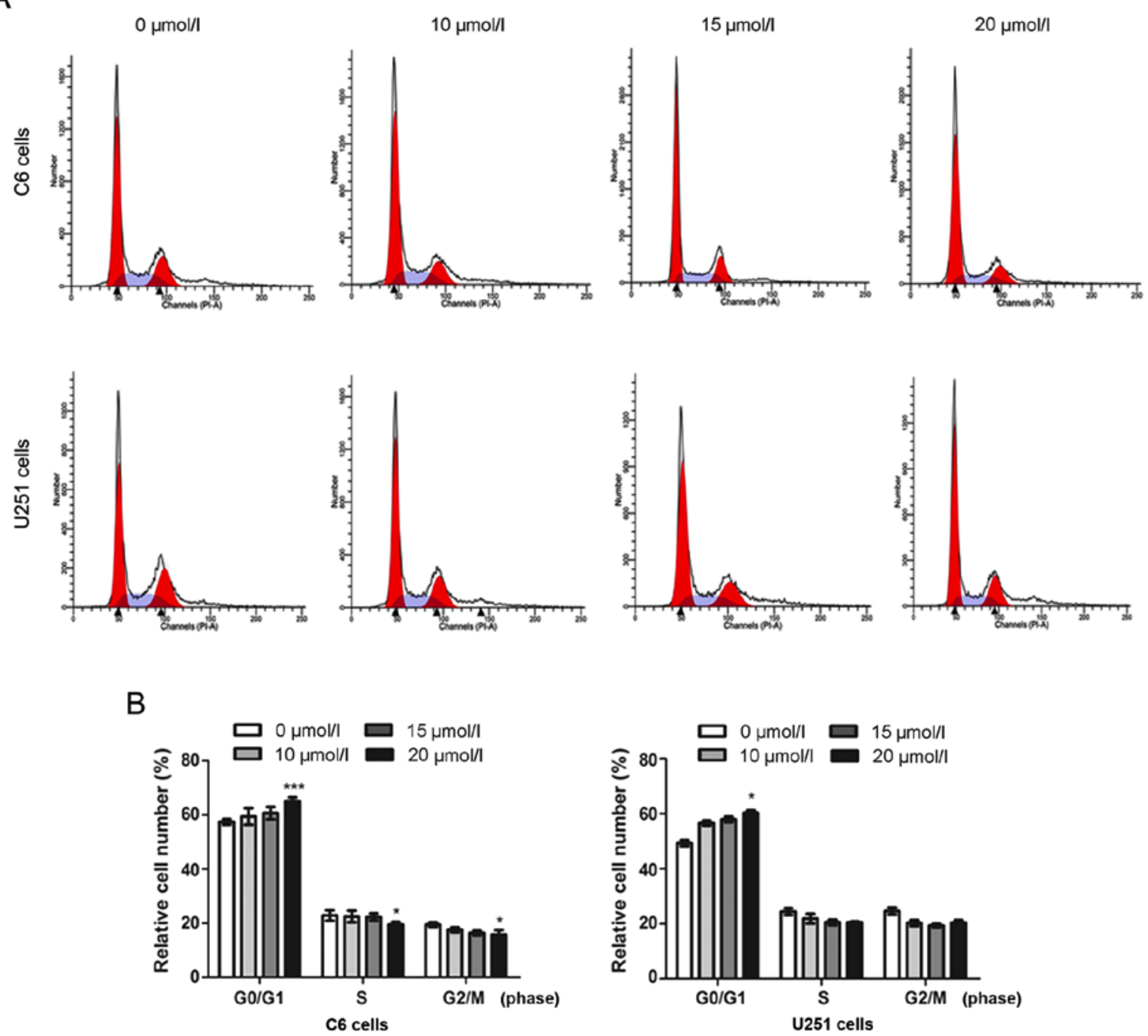

Figure 3. Cell cycle arrest effects of MOX in C6 and U251 cells. Cells were treated with various concentrations of MOX (0, 10, 15 and $20 \mu$ mol/l) for $24 \mathrm{~h}$. (A) Representative histograms for the changes in the cell cycle for C6 and U251 cells. (B) Graphs represent the percentage of cell cycle distribution at the G0/G1, S and G2/M phases in C6 and U251 cells. Data are presented as the mean \pm SD. ${ }^{~ P}<0.05$ and ${ }^{* * *} \mathrm{P}<0.001$ vs. the control. MOX, moxidectin.

All control xenografts displayed a stronger Ki-67 staining compared with that of MOX-treated mice and revealed that MOX increased the levels of cleaved caspase- 3 and cleaved caspase-9 compared with saline treated tissues (Fig. 6D). As presented in Fig. 6F, the expression of cleaved caspase- 3 and cleaved caspase- 9 increased substantially compared with the control group.

\section{Discussion}

Glioma is a complex neuroglial tumor involving the dysregulation of numerous biological pathways at multiple levels including aberrant Akt/mTOR signaling pathway, genomic aberrations and mitochondrial dysfunction $(18,26,27)$. The lack of efficacious therapeutics for glioma has necessitated the development of novel therapeutic agents. In the present study, the antiparasitic agent MOX was revealed to inhibit the viability of glioma cells in a dose-dependent manner. And certain morphological features of chromatin condensation and nuclear membrane clustering in glioma cells were observed. These results further demonstrated that apoptosis was induced following treatment with MOX. Further investigation revealed that MOX significantly induced glioma cell apoptosis by upregulating the $\mathrm{Bax} / \mathrm{Bcl}-2$ ratio and activating the caspase-3/-9 cascade. Additionally, MOX caused significant G0/G1 cell cycle arrest in glioma cells after $48 \mathrm{~h}$ of treatment determined from the decrease in CDK2, CDK4, CDK6, cyclin D1 and cyclin $\mathrm{E}$ protein expression levels. When investigated further in vivo, MOX was able to effectively suppress U251 xenograft growth. These results suggested that MOX likely represents a promising agent in the treatment of glioma.

MOX is currently being used for the treatment of onchocerciasis in humans (6). Furthermore, in a previous study, it was demonstrated that milbemycins including MOX displayed promising effects for overcoming multidrug resistance in cancer therapy (14). Considering that MOX has a wide range of biological activities, along with low neurotoxic potential, binding affinity and intrinsic activity at relevant central nervous system receptors (28), MOX is considered to be an effective compound for the treatment of glioma. Hence, the present study revealed that MOX significantly inhibited the viability of C6 and U251 cells in a dose-dependent manner. 
A
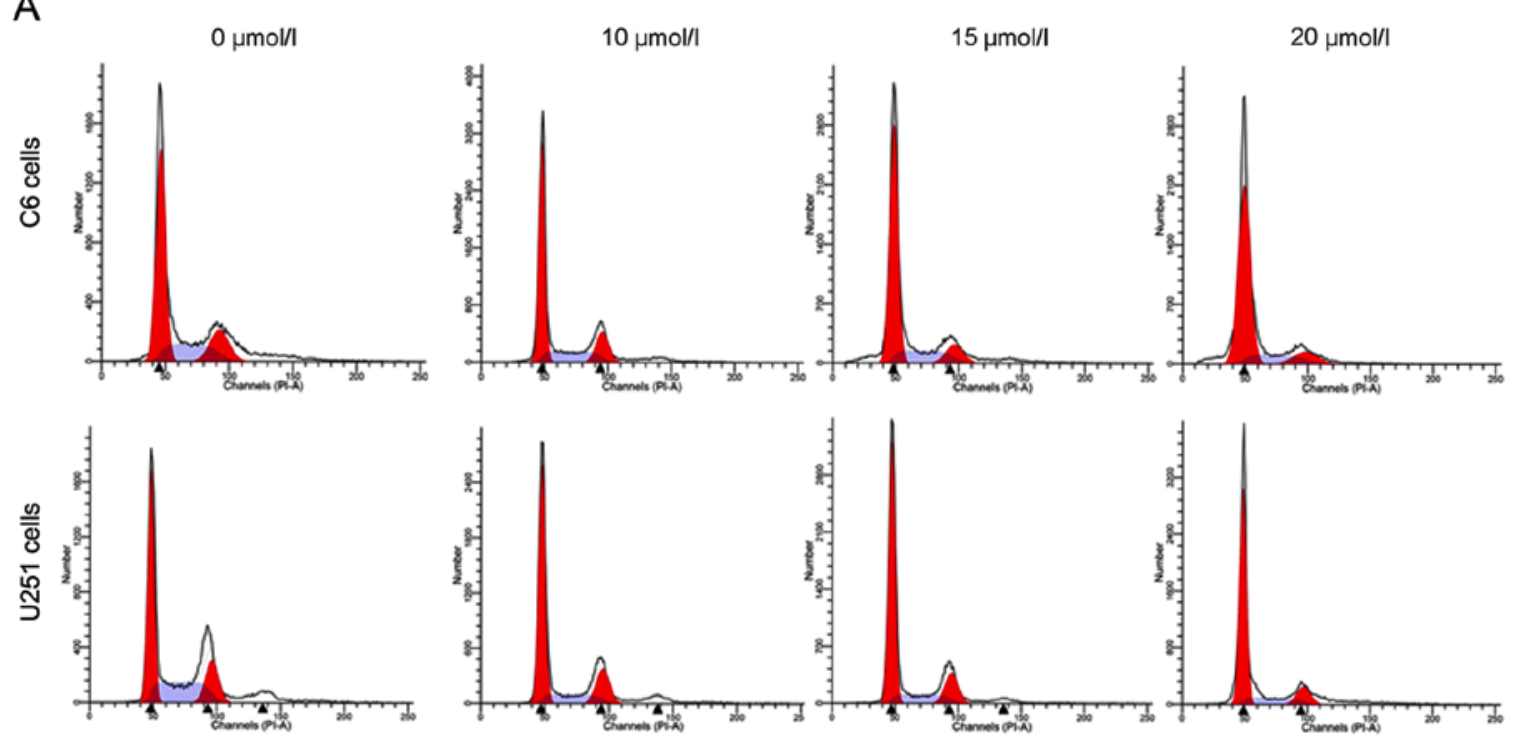

B
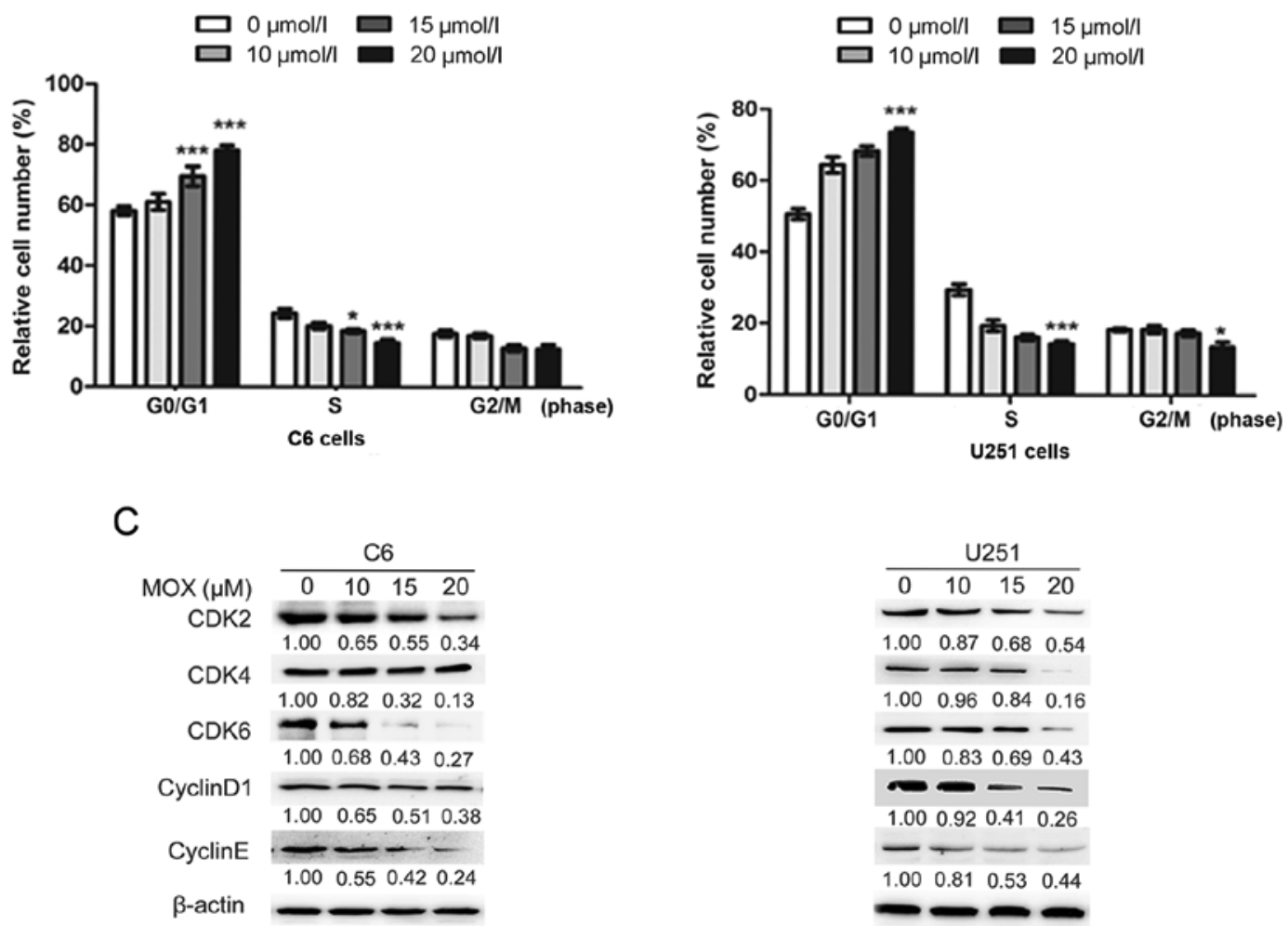

Figure 4. Cell cycle arrest effects of MOX in C6 and U251 cells. Cells were treated with various concentrations of MOX $(0,10,15$ and $20 \mu$ mol/l) for $48 \mathrm{~h}$. Following staining with propidium iodide, the DNA content was analyzed using flow cytometric analysis. (A) Representative histograms for the changes in the cell cycle for C6 and U251 cells. (B) Graphs represent the percentage cell cycle distributions at the G0/G1, S and G2/M phases in C6 and U251 cells. (C) Effect of MOX on the protein expression levels of CDK2, CDK4, CDK6, cyclin D1 and cyclin E. C6 and U251 cells were treated with indicated MOX concentrations for $48 \mathrm{~h}$ and then subjected to western blotting analysis. Data are presented as the mean $\pm \mathrm{SD}$. ${ }^{*} \mathrm{P}<0.05$ and ${ }^{* * * *} \mathrm{P}<0.001$ vs. the control. MOX, moxidectin; $\mathrm{CDK}$, cyclin-dependent kinase.

Furthermore, MOX exhibited a lesser effect on normal human astrocyte (SVG p12) cells, and half-maximal inhibitory concentration values indicated that an MOX analog is a more potent cytotoxic reagent in breast cancer cells compared with in normal breast cell (29). Consequently, the present study suggested that MOX may be used to prevent the viability of cancer cells at a low concentration and at safer concentrations.
The balance between viability and apoptosis in cancer cells is crucial for tumorigenesis $(30,31)$. Aberrant regulation of apoptotic cell death mechanisms is one of the hallmarks of cancer development and progression and numerous cancer cell types exhibit notable resistance to apoptosis signaling $(32,33)$. Apoptosis is also the main response of cells to chemotherapeutic agent $(31,34)$. Previous studies have revealed that $\mathrm{Bcl}-2$ 

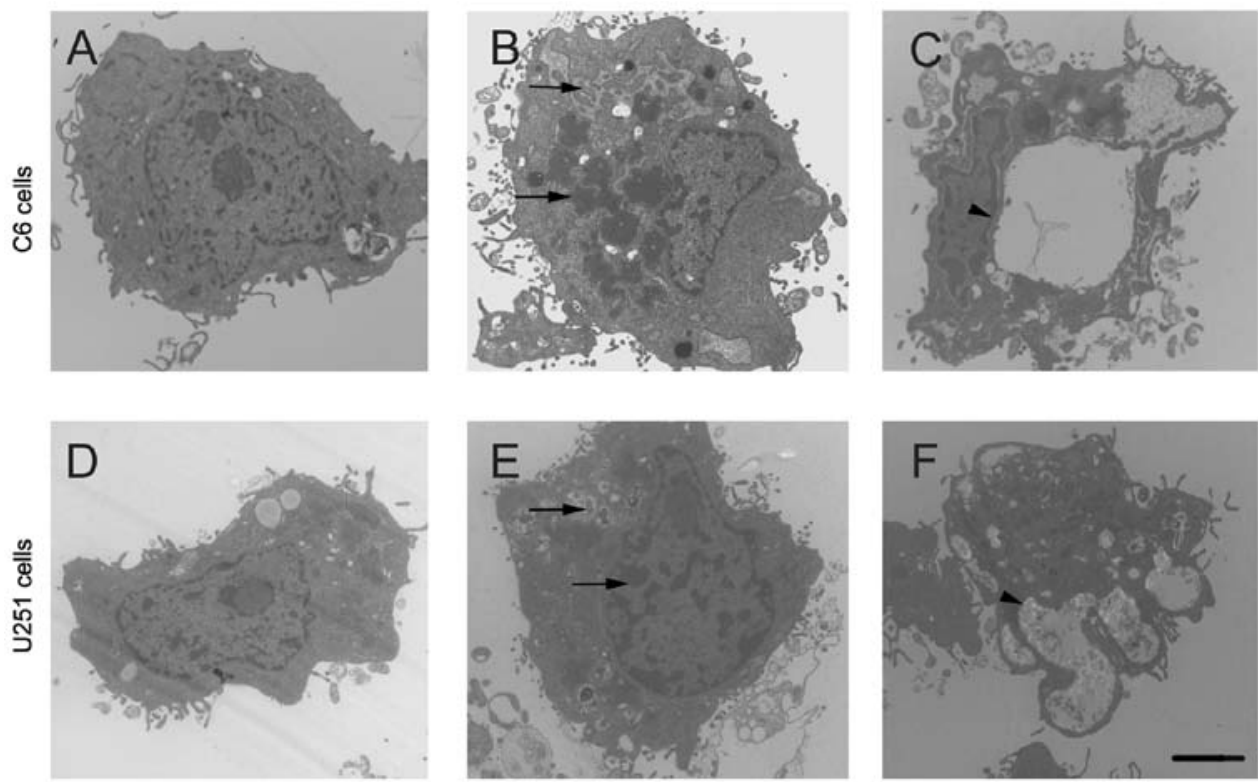

Figure 5. Morphological changes in C6 and U251 cells followed by transmission electron microscopy observation. (A and D) Control cells without MOX (B-C, E-F) Cells treated with MOX (20 $\mu \mathrm{mol} / \mathrm{l})$ for $48 \mathrm{~h}$. (B and E) Typical apoptotic changes including chromatin condensation, nuclear fragmentation and apoptotic bodies are indicated with black arrows. (C and F) Cytoplasmic and mitochondrial hypervacuolizationare indicated with black arrowheads. Scale bar, $2 \mu \mathrm{m}$. MOX, moxidectin.
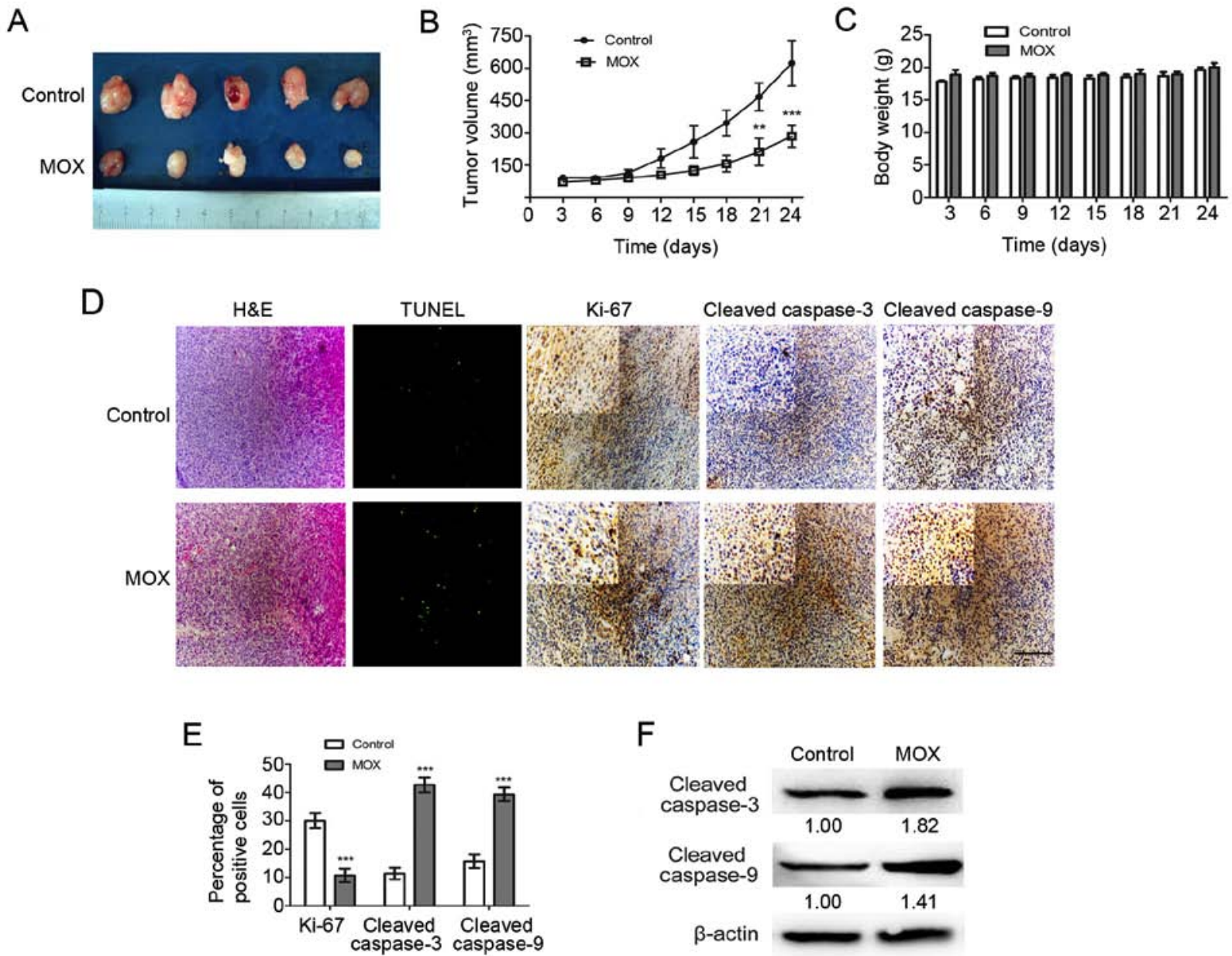

Figure 6. MOX suppressed U251 xenograft growth in vivo. Nude mice with U251 subcutaneous tumor xenografts were treated with saline or $20 \mathrm{mg} / \mathrm{kg}$ MOX every day by peritoneal injection for 3 weeks. (A) The tumors were isolated and (B) volumes were measured. (C) Charting of mouse weight with time. (D) Hematoxylin and eosin staining, terminal deoxynucleotidyl transferase-mediated dUTP nick end labeling assay and representative immunohistochemistry images of Ki-67, cleaved caspase-3 and caspase-9 in U251 xenograft tissues from vehicle or MOX-treated mice. (E) Quantitative analysis of Ki-67, cleaved caspase-3 and caspase-9-positive cells in xenograft tissues of different groups. (F) Relative amount of indicated proteins are presented. Data are presented as the mean $\pm \mathrm{SD}$. ${ }^{* * *} \mathrm{P}<0.01$ and ${ }^{* * *} \mathrm{P}<0.001$ vs. the control. MOX, moxidectin. 
family proteins, including anti-apoptotic members (Bcl-2) and pro-apoptotic members (Bax) serve an important role in mediating mitochondrial functions (35-37). In the present study, it was hypothesized that Bax and Bcl-2 were involved in the mechanism by which MOX induces cell apoptosis. Hence, the underlying mechanism of MOX-induced apoptosis in glioma cells was elucidated using western blotting. Mechanistically, it was revealed that the anticancer effect of MOX is mediated by increasing the $\mathrm{Bax} / \mathrm{Bcl}-2$ ratio in glioma cells, and that cleaved caspase-3 and cleaved caspase- 9 were also upregulated subsequent to treatment with MOX for $48 \mathrm{~h}$ in C6 and U251 cells. Furthermore, the mitochondrial apoptosis pathway is characterized by cytochrome $c$ release from the mitochondria to the cytosol, which activates the initiator caspase-9, which then targets and activates the apoptotic effector caspase-3 (38-40). The results of the present study indicated that MOX-induced apoptosis in glioma cells upregulated the expression of Bax and downregulated Bcl-2. However the mitochondrial-mediated apoptotic pathway and other induction pathways also require further in-depth study and exploration.

In addition to apoptosis, MOX also exhibited the properties of cell cycle arrest. The flow cytometry data results indicated that the cell cycle was arrested at the G0/G1 checkpoint in glioma cells subsequent to MOX treatment. The underlying mechanism of MOX on the expression of cell cycle regulation proteins in glioma cells was determined using western blotting. The results revealed that MOX was able to decrease the protein expression levels of CDK2, CDK4, CDK6, cyclin D1 and cyclin E. It has been well established that homeostasis is often disrupted by the dysregulation of the cell cycle mechanism in cancer cells $(41,42)$. Cyclin-CDK heterodimers serve an important role in regulating the progression of cells through the G1 phase of the cell cycle and initiation of DNA replication (43). Additionally, these results manifested that the cell cycle was arrested at the G0/G1 phase through downregulation of CDK4, CDK6 and cyclin D1, which induce apoptosis, and the expression of cyclin $\mathrm{E}$, which forms a complex with CDK2, peaks in the late G1 phase, and which may have resulted in cell cycle arrest in $\mathrm{G} 0 / \mathrm{G} 1$.

Furthermore, experiments in vivo were conducted according to a previous report, which indicated that the treatment of breast cancer-bearing nude mice with MOX resulted in significant inhibition of the tumor growth without overall gross toxicity (26). In the present animal study, U251 cells were selected as MOX has been demonstrated to significantly inhibit the viability of $\mathrm{U} 251$ cells in vitro, and the selected dose of the MOX injections was $20 \mathrm{mg} / \mathrm{kg}$. The reasons are as follows: First, in our previous experiment, treatment with various related drugs (ivermectin) was performed in addition to MOX. It was found that the glioma cells were treated with similar concentrations of both drugs in vitro study and these concentrations were equal to a physiological concentration. Then considering this reason and some animal studies $(7,17)$, the dose of $15 \mathrm{mg} / \mathrm{kg}$ was chosen in our preliminary animal experiment. However, it was found that MOX $(15 \mathrm{mg} / \mathrm{kg})$ had no obvious effect. Hence, the dose of MOX was increased to $20 \mathrm{mg} / \mathrm{kg}$, and it exerted an inhibitory effect on tumor growth. Additionally, in certain studies, the bioavailability of oral MOX compared with subcutaneous
MOX in alpacas was $11 \%$ (44); the bioavailability of MOX in dogs co-administered with lipids was only $40 \%$ in lymph duct-cannulated dogs (45), and the bioavailability of MOX in rats was moderate at $19 \%$ (46). Taking this into consideration, $20 \mathrm{mg} / \mathrm{kg}$ was finally selected and was considered to be an effective and safe concentration. Western blotting and immunohistochemistry analysis confirmed the increase in TUNEL, Ki-67, cleaved caspase-3 and cleaved caspase-9 following treatment with MOX. These results revealed that the subcutaneous injection of MOX may reduce the tumor mass of U251 xenografts. This means that MOX may be a novel therapeutic agent for glioma.

The present study demonstrated that MOX has an inhibitory effect on the viability of glioma cells in vitro and in vivo by inducing mitochondrial-mediated apoptosis and G0/G1 cell cycle arrest. Given these results and the fact that MOX is already clinically approved or being used in clinical trials (13), MOX may represent a potent and promising agent to combat glioma.

\section{Acknowledgements}

The authors would like to thank Dr Matthew Pona from the University of Ottawa (ON, Canada) for assisting in the preparation of the manuscript.

\section{Funding}

The present study was supported by the National Natural Science Foundation of China (grant nos. 81201723 and 81501050), the 'Young Talents' Project of Northeast Agricultural University (grant no. 14QC05), the Natural Science Foundation of Heilongjiang Province (grant no. QC2014C104) and the Heilongjiang Postdoctoral Fund (grant no. LBH-Z13027).

\section{Availability of data and materials}

All data generated or analyzed during this study are included in this published article.

\section{Authors' contributions}

AG conceived and designed the study. DS and HL researched the literature, performed analysis of data and drafted the manuscript. BQ and YL were involved in the conception of the study. $\mathrm{JL}, \mathrm{CC}, \mathrm{DZ}$ and $\mathrm{XZ}$ contributed to the design, execution, support and/or manuscript review. All the authors read and approved the final manuscript and agree to be accountable for all aspects of the research in ensuring that the accuracy or integrity of any part of the work are appropriately investigated and resolved.

\section{Ethics approval and consent to participate}

The study was performed in accordance with the ethical standards of the institutional and/or national research committee (Harbin Vic Biological Technology Development Co., Ltd., Harbin, China) and with the 1964 Helsinki declaration and its later amendments or comparable ethical standards. Ethical approval was obtained for the animal experiments. 


\section{Patient consent for publication}

Not applicable.

\section{Competing interests}

The authors declare they have no competing interests.

\section{References}

1. Gao JH, Wang ZL, Liu HH, Wang LM and Huang GH: Liposome encapsulated of temozolomide for the treatment of glioma tumor: Preparation, characterization and evaluation. Drug Discov Ther 9: 205-212, 2015.

2. Furnari FB, Fenton T, Bachoo RM, Mukasa A, Stommel JM, Stegh A, Hahn WC, Liqon KL, Louis DN, Brennan C, et al: Malignant astrocytic glioma: Genetics, biology, and paths to treatment. Genes Dev 21: 2683-2710, 2007.

3. Gilbert MR, Wang M, Aldape KD, Stupp R, Hegi ME, Jaeckle KA, Armstrong TS, Wefel JS, Won M, Blumenthal DT, et al: Dose-dense temozolomide for newly diagnosed glioblastoma: A randomized phase III clinical trial. J Clin. Oncol 31: 4085-4091, 2013.

4. Lan YL, Wang X, Xing JS, Lou JC, Ma XC and Zhang B: The potential roles of dopamine in malignant glioma. Acta Neurol Belg 117: 613-621, 2017.

5. McKellar QA and Benchaoui HA: Avermectins and milbemycins. J Vet Pharmacol Ther 19: 331-351, 1996.

6. Cotreau MM, Warren S, Ryan JL, Fleckenstein L, Vanapalli SR, Brown KR, Rock D, Chen CY and Schwertschlag US: The antiparasitic moxidectin: Safety, tolerability, and pharmacokinetics in humans. J Clin Pharmacol 43: 1108-1115, 2003.

7. Prichard R, Ménez C and Lespine A: Moxidectin and the avermectins: Consanguinity but not identity. Int J Parasitol Drugs and Drug Resist 14: 134-153, 2012.

8. Perez M, Blazquez AG, Real R, Mendoza G, Prieto JG, Merino G and Alvarez AI: In vitro and in vivo interaction of moxidectin with BCRP/ABCG2. Chem Biol Interact 180: 106-112, 2009.

9. Zulalian J, Stout SJ, Cunha AR, Garces T and Miller P: Absorption, tissue distribution, metabolism, and excretion of moxidectin in cattle. J Agric Food Chem 42: 381-387, 1994.

10. Afzal J, Stout SJ and da Cunha AR and Miller P: Moxidectin: Absorption, tissue distribution, excretion, and biotransformation of 14C-labeled moxidectin in sheep. J Agric Food Chem 42: 1767-1773, 1994.

11. Afzal J, Burke AB, Batten PL, DeLay RL and Miller P: Moxidectin: Metabolic fate and blood pharmacokinetics of ${ }^{14}$ C-labeled moxidectin in horses. J Agric Food Chem 45: 3627-3633, 1997.

12. Traversa D, Di Cesare A, Milillo P, Lohr B, Iorio R, Pampurini F, Schaper R, Paoletti B and Heine J: Efficacy and safety of imidacloprid $10 \%$ /moxidectin $1 \%$ spot-on formulation in the treatment of feline aelurostrongylosis. Parasitol Res 105 (Suppl 1): S55-S62, 2009.

13. Verma M, Pathak M, Shahab M, Singh K, Mitra K and Misra-Bhattacharya S: Moxidectin causes adult worm mortality of human lymphatic filarial parasite Brugia malayi in rodent models. Folia Parasitol 61: 561-570, 2014.

14. Gao A, Wang X, Xiang W, Liang H, Gao J and Yan Y: Reversal of P-glycoprotein-mediated multidrug resistance in vitro by doramectin and nemadectin. J Pharm Pharmacol 62: 393-399, 2010.

15. Korystov YN, Ermakova NV, Sterlina LN, Levitman MK, Shaposhnikova VV, Mosin VA, Drinyaev VA, Kruglyak EB, Novik TS and Sterlina TS: Avermectins inhibit multidrug resistance of tumor cells. Eur J Pharmacol 493: 57-64, 2004

16. Mani T, Bourguinat C, Keller K, Asraf S, Blagburn B and Prichard RK: Interaction of macrocyclic lactones with a Dirofilaria immitis P-glycoprotein. Int J Parasitol 46: 631-40, 2016.

17. Dou Q, Chen HN, Wang K, Yuan K, Lei Y, Li K, Lan J, Chen Y, Huang Z, Xie N, et al: Ivermectin induces cytostatic autophagy by blocking the PAK1/Akt axis in breast cancer. Cancer Res 76 : 4457-4469, 2016.

18. Liu YY, Fang SS, Sun QS and Liu B: Anthelmintic drug ivermectin inhibits angiogenesis, growth and survival of glioblastoma through inducing mitochondrial dysfunction and oxidative stress. Biochem Biophys Res Commun 480: 415-421, 2016.
19. Farkas R, Hell E and Palfi T: The efficacy of four anthelmintics against small strongyles in a stud farm in Hungary. Magyar Allatorvosok Lapja 128: 291-297, 2006.

20. Lespine A, Martin S, Dupuy J, Roulet A, Pineau T, Orlowski S and Alvinerie $\mathrm{M}$ : Interaction of macrocyclic lactones with P-glycoprotein: Structure-affinity relationship. Eur J Pharm Sci 30: 84-94, 2007.

21. Mounsey KE, Bernigaud C, Chosidow O and McCarthy JS: Prospects for moxidectin as a new oral treatment for human scabies. PLoS Negl Trop Dis 10: e0004389, 2016.

22. Fazzio LE, Streitenberger N, Galvan WR, Sánchez RO, Gimeno EJ and Sanabria RE: Efficacy and productive performance of moxidectin in feedlot calves infected with nematodes resistant to ivermectin. Vet Parasitol 223: 26-29, 2016.

23. Lloberas M, Alvarez L, Entrocasso C, Virkel G, Ballent M, Mate L, Lanusse $\mathrm{C}$ and Lifschitz A: Comparative tissue pharmacokinetics and efficacy of moxidectin, abamectin and ivermectin in lambs infected with resistant nematodes: Impact of drug treatments on parasite P-glycoprotein expression. Int. J Parasitol Drugs Drug Resist 3: 20-27, 2013.

24. Jiang Z, Chai J, Chuang HH, Li S, Wang T, Cheng Y, Chen W and Zhou D: Artesunate induces G0/G1 cell cycle arrest and iron-mediated mitochondrial apoptosis in A431 human epidermoid carcinoma cells. Anticancer Drugs 23: 606-613, 2012.

25. Wu X, Wu MY, Jiang M, Zhi QM, Bian J, Xu MD, Gong FR, Hou J, Tao M, Shou LM, et al: TNF- $\alpha$ sensitizes chemotherapy and radiotherapy against breast cancer cells. Cancer Cell Int 17: 13, 2017.

26. Guichet PO, Guelfi S, Ripoll C, Teigell M, Sabourin JC, Bauchet L, Rigau V, Rothhut B and Hugnot JP: Asymmetric distribution of GFAP in glioma multipotent Cells. PLoS One 11: e0151274. 2016.

27. Zhou XM, Sun R, Luo DH, Sun J, Zhang MY, Wang MH, Yang Y, Wang HY and Mai SJ: Upregulated TRIM29 promotes proliferation and metastasis of nasopharyngeal carcinoma via PTEN/AKT/mTOR signal pathway. Oncotarget 7: 13634-13650. 2016.

28. Janko C and Geyer J: Moxidectin has a lower neurotoxic potential but comparable brain penetration in P-glycoprotein-deficient CF-1 mice compared to ivermectin. J Vet Pharmacol Ther 36: 275-284, 2013.

29. Xiang WS, Gao AL, Liang HS, Li CY, Gao JG, Wang Q, Shuang B, Zhang J, Yan YJ and Wang XJ: Reversal of P-glycoprotein-mediated multidrug resistance in vitro by milbemycin compounds in adriamycin-resistant human breast carcinoma (MCF-7/adr) cells. Toxicol In Vitro 24, 1474-1481, 2010.

30. Mattern J and Volm M: Imbalance of cell proliferation and apoptosis during progression of lung carcinomas. Anticancer Res 24: 4243-4246, 2004.

31. Wong RS: Apoptosis in cancer: From pathogenesis to treatment. J Exp Clin Cancer Res 30: 87, 2011.

32. Danial NN: BCL-2 family proteins: Critical checkpoints of apoptotic cell death. Clin Cancer Res 13: 7254-7263, 2007.

33. Xiong S, Mu T, Wang G, and Jiang X: Mitochondria-mediated apoptosis in mammals. Protein Cell 5: 737-749, 2014.

34. Ekert PG, Read SH, Silke J, Marsden VS, Kaufmann H, Hawkins H, Hawkins CJ, Gerl R, Kumar S and Vaux DL: Apaf-1 and caspase-9 accelerate apoptosis, but do not determine whether factor-deprived or drug-treated cells die. J Cell Biol 165: 835-842, 2004.

35. Youle RJ and Strasser A: The BCL-2 protein family: Opposing activities that mediate cell death. Nat Rev Mol Cell Biol 9: 47-59, 2008.

36. Kang $\mathrm{MH}$ and Reynolds CP: Bcl-2 inhibitors: Targeting mitochondrial apoptotic pathways in cancer therapy. Clin Cancer Res 15: 1126-1132, 2009.

37. Liang BX, Liu ZY, Cao YN, Zhu C, Zuo Y, Huang L, Wen G, Shang N, Chen Y, Yue X, et al: MC37, a new mono-carbonyl curcumin analog, induces G2/M cell cycle arrest and mitochondria-mediated apoptosis in human colorectal cancer cells. Eur J Pharmacol 796: 139-148, 2017.

38. Gogvadze V, Orrenius S and Zhivotovsky B: Multiple pathways of cytochrome c release from mitochondria in apoptosis. Biochim Biophys Acta 1757: 639-647, 2006.

39. Singh PK and Kumar A: Mitochondria mediates caspase-dependent and independent retinal cell death in Staphylococcus aureus endophthalmitis. Cell Death Discov 2: 16034, 2016. 
40. Lee JH, Jung JY, Jeong YJ, Park JH, Yang KH, Yang KH, Choi NK, Kim SH, and Kim WJ: Involvement of both mitochondrial- and death receptor-dependent apoptotic pathways regulated by Bcl-2 family in sodium fluoride-induced apoptosis of the human gingival fibroblasts. Toxicology 243: 340-347, 2008.

41. Wan D, Jiang C, Hua X, Wang T and Chai M: Cell cycle arrest and apoptosis induced by aspidin PB through the p53/p21 and mitochondria-dependent pathways in human osteosarcoma cells. Anticancer Drugs 26: 931-941, 2015.

42. McGinnis GR and Young ME: Circadian regulation of metabolic homeostasis: Causes and consequences. Nat Sci Sleep 8: 163-180, 2016.

43. Lin CJ, Chang YA, Lin YL, Liu SH, Chang CK and Chen RM: Preclinical effects of honokiol on treating glioblastoma multiforme via G1 phase arrest and cell apoptosis. Phytomedicine 23: 517-527, 2016

44. Cocquyt CM, Van Amstel S, Cox S, Rohrbach B and Martín-Jiménez T: Pharmacokinetics of moxidectin in alpacas following administration of an oral or subcutaneous formulation. Res Vet Sci 105: 160-164, 2016.
45. Lespine A, Chanoit G, Bousquet-Melou A, Lallemand E, Bassissi FM, Alvinerie M and Toutain PL: Contribution of lymphatic transport to the systemic exposure of orally administered moxidectin in conscious lymph duct-cannulated dogs. Eur J Pharm Sci 27: 37-43, 2006.

46. Dupuy J, Larrieu G, Sutra JF, Eeckhoutte C and Alvinerie M: Influence of verapamil on the efflux and metabolism of $14 \mathrm{C}$ moxidectin in cultured rat hepatocytes. J Vet Pharmacol Ther 24: 171-177, 2001.

This work is licensed under a Creative Commons Attribution-NonCommercial-NoDerivatives 4.0 International (CC BY-NC-ND 4.0) License. 